\title{
Comparing the mortality risks of nursing professionals with diabetes and general patients with diabetes: a nationwide matched cohort study
}

Hsiu-Ling Huang ${ }^{1,2+}$, Chuan-Yu Kung ${ }^{3}$, Cheng-Chin Pan ${ }^{4+}$, Pei-Tseng Kung ${ }^{5}$, Shun-Mu Wang ${ }^{1}$, Wen-Yu Chou ${ }^{6}$ and Wen-Chen Tsai ${ }^{6 *}$

\begin{abstract}
Background: Nursing professionals have received comprehensive medical education and training. However, whether these medical professionals exhibit positive patient care attitudes and behaviors and thus reduce mortality risks when they themselves are diagnosed with chronic diseases is worth exploring. This study compared the mortality risks of female nurses and general patients with diabetes and elucidated factors that caused this difference.

Methods: A total of 510,058 female patients newly diagnosed with diabetes between 1998 and 2006 as recorded in the National Health Insurance Research Database were the participants in this study. Nurses with diabetes and general population with diabetes were matched with propensity score method in a 1:10 ratio. The participants were tracked from the date of diagnosis to 2009. The Cox proportional hazards model was utilized to compare the mortality risks in the two groups.

Results: Nurses were newly diagnosed with diabetes at a younger age compared with the general public $(42.01 \pm 12$. 03 y vs. $59.29 \pm 13.11$ y). Nevertheless, the matching results showed that nurses had lower mortality risks (HR: 0.53, $95 \%$ Cl: $0.38-0.74)$ and nurses with diabetes in the $<35$ and $35-44$ age groups exhibited significantly lower mortality risks compared with general patients (HR: 0.23 and 0.36). A further analysis indicated that the factors that influenced the mortality risks of nurses with diabetes included age, catastrophic illnesses, and the severity of diabetes complications.
\end{abstract}

Conclusion: Nurses with diabetes exhibited lower mortality risks possibly because they had received comprehensive medical education and training, may had more knowledge regarding chronic disease control and change their lifestyles. The results can serve as a reference for developing heath education, and for preventing occupational hazards in nurses.

Keywords: Nursing health education, Occupational health, Nurse with diabetes, Mortality risk, National Health Insurance, Cohort study

\section{Background}

According to statistics provided by the International Diabetes Federation (IDF), approximately 3.8 million people die of diabetes-related diseases annually in the world [1]. In Taiwan, a marked increase has been observed in the female population diagnosed with diabetes,

\footnotetext{
* Correspondence: wtsai@mail.cmu.edu.tw

${ }^{\dagger}$ Equal contributors

${ }^{6}$ Department of Health Services Administration, China Medical University, 91, Hsueh-Shih Road, Taichung, Taiwan 40402, Republic Of China

Full list of author information is available at the end of the article
}

which has been the third leading cause of death for Taiwanese women since 2003 [2]. Type 2 diabetes is one of the most prominent chronic diseases in the world [3], and no cure has been identified. Patients with Type 2 diabetes must rely on long-term treatment and care, and complications are common. However, mortality rates and the occurrence of severe complications can be minimised if sufficient daily care is maintained [4].

There are many studies related to health-seeking and illness behaviors, the majority of which focus on specific types of patients $[5,6]$. The health-belief model, the 
behavior model of health service utilization, the general theory of health-seeking, and the Andersen behavioral model all describe the basic foundation for the determinants of various diseases. A limited number of studies has examined the behavior of disease-affected health care providers to determine whether the influence on their performance-related behavior by their medical knowledge has been investigated $[7,8]$. Nursing professionals have received comprehensive medical education and training, and therefore, they play a vital role in health care [9]. However, whether these medical professionals exhibit positive patient care attitudes and behaviors and thus reduce mortality risks when they themselves are diagnosed with chronic diseases is worth exploring.

Implemented since 1995, the National Health Insurance (NHI) is a state-run, mandatory single-payer insurance system in Taiwan. As of 2012, $99.85 \%$ of the Taiwanese population was covered by the system [10]. The NHI covers all prescription medication, examination, and treatment administered during outpatient, inpatient, and emergency visits. The NHI database holds the medical information of all insured patients, including the treatment records for chronic diseases such as diabetes $[11,12]$.

In this study, the NHI Research Database (NHIRD) was employed to compare mortality risks in nursing professionals with diabetes and general patients with diabetes and identify factors that resulted in this difference. The results were used to explore whether treatment effectiveness was affected by the medical education the nursing professionals with diabetes had received and whether the knowledge they possessed reduced the relative mortality risk. The findings of this study can serve as a reference for relevant units to promote health knowledge and the health education regarding chronic diseases.

\section{Methods}

\section{Setting and study population}

A retrospective cohort study was conducted based on secondary data obtained from the NHIRD, and the study population was nursing professionals and general patients newly diagnosed with diabetes between 1998 and 2006. Furthermore, the participants were tracked from the date of diagnosis to death, and surviving participants were observed until December 31, 2009.

For the nursing professionals identification, we used the registry for medical personnel (PER) from the NHI. We include participant who already had been a nursing professional when she was newly diagnosed with diabetes. The nursing professionals examined in this study were registered nurses and licensed practical nurses that were registered or licensed before December 31, 2009; nursing professionals that were diagnosed with diabetes before they were licensed or registered were excluded from this study. Patients that were not registered or licensed as nursing or medical professionals (such as physical therapists, nutritionists, dentists, and physicians etc.) by December 31, 2009 were considered general patients in this study. Participants that died during the observation period and were therefore withdrawn from the NHI system (hence no additional treatment information can be obtained) were defined as deaths [13].

In consideration of the fact that nursing professionals are predominantly female (approximately $98.92 \%$ [14]), we used female patients newly diagnosed with diabetes as the participants. For a comparison, we used a propensity score matching method as a control for age, monthly salary, urbanization of residence, catastrophic illnesses, CCI, and DCSI at a 1:10 ratio (nursing professionals with diabetes: general patients with diabetes) to account for a selection bias and to obtain two groups of participants that exhibited no statistical differences in their demographic data or health status (Table 1).

To protect the confidentiality of the participants, we removed identification numbers from the data; individual participants were thus unidentifiable. The study was approved by the Institutional Review Board of the China Medical University and Hospital (IRB No.: CMUH 20130326C).

\section{Study design}

In this study, newly diagnosis was considered to refer to patients who had been diagnosed with diabetes as a primary or secondary diagnosis (ICD-9-CM: 250 or Acode: A181) and had made 3 or more clinic visits or been hospitalized at least once within 365 days [15]. Patients that had received dialysis for less than 90 days following diagnosis or were younger than 20 or older than 90 years of age were excluded from the study. In addition, patients with Type 1 diabetes (ICD-9-CM: 6488), gestational diabetes (ICD-9-CM: 7751), neonatal diabetes (ICD-9-CM: 7902), and impaired glucose tolerance (ICD-9-CM: 6480) were also excluded.

Demographic data variables were sex, age, urbanization level of residence area (overall 7 levels; Level 1 was the most urbanized [16]), socioeconomic status (determined by the insured monthly salary). Presence of catastrophic illnesses or injuries were defined by National Health Insurance Administration in Taiwan, including 30 categories of major illnesses (e.g., stroke, hemophilia, type I diabetes, end-stage renal disease, cancer, autoimmune diseases, congenital factor disorder, Chronic Mental Illness etc.) [17]. In this study, presence of catastrophic illness was classified as yes or no. According to Deyo et al. [18], the Charlson comorbidity index (CCI) 
Table 1 Patient demographics before and after propensity score (PS) matching

\begin{tabular}{|c|c|c|c|c|c|c|c|c|c|c|c|c|c|c|}
\hline \multirow[t]{3}{*}{ Variables } & \multicolumn{7}{|c|}{ Before PS matching } & \multicolumn{7}{|c|}{ After PS matching (10:1) } \\
\hline & \multicolumn{2}{|c|}{ Total } & \multicolumn{2}{|c|}{ General patients } & \multicolumn{2}{|l|}{ Nurse } & \multirow[t]{2}{*}{$P$-value } & \multicolumn{2}{|c|}{ Total } & \multicolumn{2}{|c|}{ General patients } & \multicolumn{2}{|l|}{ Nurse } & \multirow[t]{2}{*}{$P$-value } \\
\hline & $N$ & $\%$ & N & $\%$ & $N$ & $\%$ & & N & $\%$ & N & $\%$ & N & $\%$ & \\
\hline Total patients & 518,058 & 100.00 & 516,100 & 99.62 & 1958 & 0.38 & & 18,601 & 100.00 & 16,910 & 90.91 & 1691 & 9.09 & \\
\hline Age & & & & & & & $<0.001$ & & & & & & & 0.928 \\
\hline$<25$ & 3092 & 0.60 & 2913 & 0.56 & 179 & 9.14 & & 1194 & 6.42 & 1083 & 6.40 & 111 & 6.56 & \\
\hline $25-34$ & 15,361 & 2.97 & 14,951 & 2.90 & 410 & 20.94 & & 3214 & 17.28 & 2933 & 17.34 & 281 & 16.62 & \\
\hline $35-44$ & 53,986 & 10.42 & 53,436 & 10.35 & 550 & 28.09 & & 5568 & 29.93 & 5069 & 29.98 & 499 & 29.51 & \\
\hline $45-54$ & 127,935 & 24.70 & 127,351 & 24.68 & 584 & 29.83 & & 6059 & 32.57 & 5494 & 32.49 & 565 & 33.41 & \\
\hline $55-64$ & 136,540 & 26.36 & 136,363 & 26.42 & 177 & 9.04 & & 1894 & 10.18 & 1717 & 10.15 & 177 & 10.47 & \\
\hline$\geqq 65$ & 181,144 & 34.97 & 181,086 & 35.09 & 58 & 2.96 & & 672 & 3.61 & 614 & 3.63 & 58 & 3.43 & \\
\hline Average age (Mean, Std) & 59.22 & 13.15 & 59.29 & 13.11 & 42.01 & 12.03 & & 44.14 & 11.86 & 44.19 & 11.87 & 43.60 & 11.78 & \\
\hline Monthly salary (NT\$) & & & & & & & $<0.001$ & & & & & & & 0.659 \\
\hline $\begin{array}{l}\text { Low-income } \\
\text { household }\end{array}$ & 5010 & 0.97 & 5009 & 0.97 & 1 & 0.05 & & 3 & 0.02 & 2 & 0.01 & 1 & 0.06 & \\
\hline$\leqq 17,280$ & 35,033 & 6.77 & 34,873 & 6.77 & 160 & 8.17 & & 1826 & 9.82 & 1670 & 9.88 & 156 & 9.23 & \\
\hline $17,281 \sim 22,800$ & 295,781 & 57.20 & 295,390 & 57.34 & 391 & 19.97 & & 4312 & 23.18 & 3922 & 23.19 & 390 & 23.06 & \\
\hline $22,801 \sim 28,800$ & 77,247 & 14.94 & 77,044 & 14.96 & 203 & 10.37 & & 2011 & 10.81 & 1819 & 10.76 & 192 & 11.35 & \\
\hline $28,801 \sim 36,300$ & 30,974 & 5.99 & 30,745 & 5.97 & 229 & 11.70 & & 2015 & 10.83 & 1829 & 10.82 & 186 & 11.00 & \\
\hline $36,301 \sim 45,800$ & 33,977 & 6.57 & 33,470 & 6.50 & 507 & 25.89 & & 4128 & 22.19 & 3739 & 22.11 & 389 & 23.00 & \\
\hline $45,801 \sim 57,800$ & 19,896 & 3.85 & 19,584 & 3.80 & 312 & 15.93 & & 2540 & 13.66 & 2311 & 13.67 & 229 & 13.54 & \\
\hline$\geqq 57,801$ & 19,206 & 3.71 & 19,051 & 3.70 & 155 & 7.92 & & 1766 & 9.49 & 1618 & 9.57 & 148 & 8.75 & \\
\hline Missing data & 934 & & 934 & & & & & & & & & & & \\
\hline Urbanization of residence area & & & & & & & $<0.001$ & & & & & & & 0.181 \\
\hline Level 1 & 141,455 & 27.35 & 140,779 & 27.33 & 676 & 34.53 & & 6593 & 35.44 & 5998 & 35.47 & 595 & 35.19 & \\
\hline Level $2 \& 3$ & 231,299 & 44.73 & 230,365 & 44.72 & 934 & 47.70 & & 9149 & 49.19 & 8334 & 49.28 & 815 & 48.20 & \\
\hline Level 4 \& 5 & 94,836 & 18.34 & 94,589 & 18.36 & 247 & 12.61 & & 2145 & 11.53 & 1944 & 11.50 & 201 & 11.89 & \\
\hline Level $6 \& 7$ & 49,533 & 9.58 & 49,432 & 9.60 & 101 & 5.16 & & 714 & 3.84 & 634 & 3.75 & 80 & 4.73 & \\
\hline Missing data & 935 & & 935 & & & & & & & & & & & \\
\hline Catastrophic illnesses & & & & & & & 0.318 & & & & & & & 0.158 \\
\hline No & 503,285 & 97.15 & 501,375 & 97.15 & 1910 & 97.55 & & 18,200 & 97.84 & 16,554 & 97.89 & 1646 & 97.34 & \\
\hline Yes & 14,773 & 2.85 & 14,725 & 2.85 & 48 & 2.45 & & 401 & 2.16 & 356 & 2.11 & 45 & 2.66 & \\
\hline
\end{tabular}

Average age (Mean, Std)

$7,281 \sim 22,800$

$36,301 \sim 45,800$

Level 4 \& 5

Level $6 \& 7$

ilnesses

Yes
14,77

2.85

401
2.16
356
2.11 
Table 1 Patient demographics before and after propensity score (PS) matching (Continued)

Moderate to severe kidney

disease

0.218

0.085

$\begin{array}{lllllll}\text { No } & 440,556 & 85.04 & 438,871 & 85.04 & 1685 & 86.06 \\ \text { Yes } & 77,502 & 14.96 & 77,229 & 14.96 & 273 & 13.94\end{array}$

$\mathrm{CCl}$

0
$1 \sim 3$
$4 \sim 6$
$7 \sim 9$
$\geqq 10$

Average CCI (Mean, Std)

DCSI

0
1
2
$\geqq 3$

$\begin{array}{llllll}8776 & 1.69 & 8751 & 1.70 & 25 & 1.28\end{array}$

$\begin{array}{llllll}129,044 & 24.91 & 128,410 & 24.88 & 634 & 32.38\end{array}$

$\begin{array}{llllll}148,079 & 28.58 & 147,421 & 28.56 & 658 & 33.61\end{array}$

$\begin{array}{llllll}125,612 & 24.25 & 125,197 & 24.26 & 415 & 21.20\end{array}$

$\begin{array}{llllll}106,547 & 20.57 & 106,321 & 20.60 & 226 & 11.54\end{array}$

Average DCSI (Mean, Std)

$6.33 \quad 3.78$

$$
6.33
$$

20.60

5.41

3.39

Abbreviations: CCI Charlson Comorbidity Index, DCSI Diabetes Complications Severity Index, PS propensity score

It's 30 New Taiwan Dollar (NT\$) per US dollar

Urbanization level of residence area (overall 7 levels; Level 1 was the most urbanized)

The $p$ values less than 0.05 was considered statistically significant 
involves 17 comorbidities weighted based on severity. In addition, the definition of diabetes complication severity index (DCSI) developed by Young et al. [19] was used, and complications observed upon diagnosis or prior to the last day of observation were identified.

\section{Statistical analyses}

Statistical Analysis System Version 9.3 was employed and chi-square tests were conducted to compare mortality rates in nursing professionals and general patients diagnosed with diabetes. The Cox proportional hazards model was utilized to compare the relative mortality risks between the two groups when all of the other variables were controlled. The model was used to identify factors that affect mortality risks in nursing professionals diagnosed with diabetes. Hazard ratios (HRs) and $95 \%$ CIs were derived from Cox proportional hazards models. In this study, the $p$ values less than 0.05 was considered statistically significance.

\section{Results}

\section{Participants demographics}

The number of female patients that were newly diagnosed with diabetes between 1998 and 2006 and satisfied the participant inclusion criteria was 518,058 (Table 1). Propensity score matching was performed at a 1:10 ratio to control for selection bias, yielding a sample of 18,601 (nursing professionals with diabetes vs. general patients with diabetes $=1691$ vs. 16,910). The participants were tracked until the end of 2009 and the average tracking period was $6.73 \pm 2.61$ years (nursing professionals with diabetes vs. general patients with diabetes $=6.80 \pm 2.60$ y vs. $6.72 \pm 2.61$ y).

Before propensity score matching, among the population of female patients that were newly diagnosed with diabetes and who satisfied the participant selection criteria, significant differences were observed between the two groups in age, monthly salary, the level of urbanization of their residence, $\mathrm{CCI}$, and DCSI $(P<0 \quad .05)$. Regarding age, the nursing professionals newly diagnosed with diabetes were younger on average than the general patients $(42.01 \pm 12.03$ y vs. $59.29 \pm 13.11 \mathrm{y})$. The monthly salaries of the nursing professionals were generally higher than those of the general public; $49.74 \%$ of the nursing professionals had monthly salaries higher than NT $\$ 36,301$, whereas only $10.3 \%$ of the general patients had salaries at or above that level. Regarding the CCI and DCSI, the average CCI $(5.41 \pm 3.39)$ and DCSI $(0.37 \pm 0.76)$ of the nursing professionals were lower than those of the general patients, indicating that compared with the general public diagnosed with diabetes, the nursing professionals were healthier when newly diagnosed with diabetes (Table 1).
After the propensity score matching, there were no significant differences in the covariates between the two groups $(P>0.05)$.

\section{Relative mortality risks in nursing patients with diabetes and general patients with diabetes}

A bivariate analysis regarding the survival of nursing professionals and general patients diagnosed with diabetes (Table 2) showed that compared with the nursing professionals, the general patients exhibited a higher mortality rate as of December 31, 2009, when the observation period ended (4.45\% vs. $2.19 \%)$ and the difference reached statistical significance $(P<0.05)$.

After controlling for other factors, Cox proportional hazards models were used to identify the mortality rate for the nursing professionals and general patients. An analysis of the data in Table 3 and Fig. 1 showed that the mortality risks of nursing professionals were lower than those of general patients (Adj. HR: 0.53, 95 \% CI: 0.38-0.74). In order to compare the two groups of the same age, we further performed the stratified analyses in order to compare the two groups in terms of their mortality risk (Table 3). Regarding age, when grouped into 10-year ranges, nursing professionals younger than 35 years of age or between 35 and 44 years of age exhibited a lower mortality risk than did general patients in the same age groups (Adj. HR: 0.23 and $0.35, P<0.05$ ). Although nursing professionals older than 45 years of age had a lower mortality risk than did general patients in the same age group, this difference did not reach the level of significance $(P>0.05)$. Furthermore, whatever the CCI was, the nursing professionals had significantly lower mortality risks than did the general patients $(P<0.05)$. Regarding the DCSI, nursing professionals had lower mortality risks than did the general patients only when DCSI $\leqq 1$ (Adj. HR: 0.40); when DCSI $>2$, no significant difference was observed between the 2 groups $(P>0.05)$.

\section{Factors that affect the mortality of nursing professionals with diabetes}

As shown in Table 4, factors that affected the mortality of nursing professionals with diabetes included age, catastrophic illnesses, and DCSI. The mortality risk of nursing professionals 65 years of age or older was 23.54 times that of nursing professionals younger than 35 years of age (95 \% CI: 5.02-110.33). The mortality risk of nursing professionals with catastrophic illnesses was 6.90 times that of those without such conditions (95 \% CI: 2.92-16.29). In addition, the mortality risk of nursing professionals with a DCSI $\geqq 3$ was 2.72 times that of those with a DCSI $\leqq 1$ (95 \% CI: 1.20-6.16). 
Table 2 Bivariate analysis of participant survival

\begin{tabular}{|c|c|c|c|c|c|c|c|}
\hline \multirow[t]{2}{*}{ Variables } & \multicolumn{2}{|l|}{ Total } & \multicolumn{2}{|l|}{ Survival } & \multicolumn{2}{|l|}{ Death } & \multirow[t]{2}{*}{$P$-value } \\
\hline & $N$ & $\%$ & $N$ & $\%$ & N & $\%$ & \\
\hline Total patients & 18,601 & 100.00 & 17,812 & 95.76 & 789 & 4.24 & \\
\hline \multicolumn{3}{|l|}{ Nurses or general patients } & & & & & $<0.001$ \\
\hline General & 16,910 & 90.91 & 16,158 & 95.55 & 752 & 4.45 & \\
\hline Nurses & 1691 & 9.09 & 1654 & 97.81 & 37 & 2.19 & \\
\hline Age & & & & & & & $<0.001$ \\
\hline$<25$ & 1194 & 6.42 & 1173 & 98.24 & 21 & 1.76 & \\
\hline $25-34$ & 3214 & 17.28 & 3134 & 97.51 & 80 & 2.49 & \\
\hline $35-44$ & 5568 & 29.93 & 5386 & 96.73 & 182 & 3.27 & \\
\hline $45-54$ & 6059 & 32.57 & 5864 & 96.78 & 195 & 3.22 & \\
\hline $55-64$ & 1894 & 10.18 & 1763 & 93.08 & 131 & 6.92 & \\
\hline$\geqq 65$ & 672 & 3.61 & 492 & 73.21 & 180 & 26.79 & \\
\hline Average age (Mean, Std) & 44.14 & 11.86 & 43.73 & 11.49 & 53.27 & 15.83 & \\
\hline Monthly salary (NT\$) & & & & & & & $<0.001$ \\
\hline$\leqq 17,280$ & 1829 & 9.83 & 1752 & 95.79 & 77 & 4.21 & \\
\hline $17,281 \sim 22,800$ & 4312 & 23.18 & 4135 & 95.90 & 177 & 4.10 & \\
\hline $22,801 \sim 28,800$ & 2011 & 10.81 & 1854 & 92.19 & 157 & 7.81 & \\
\hline $28,801 \sim 36,300$ & 2015 & 10.83 & 1948 & 96.67 & 67 & 3.33 & \\
\hline $36,301 \sim 45,800$ & 4128 & 22.19 & 3970 & 96.17 & 158 & 3.83 & \\
\hline $45,801 \sim 57,800$ & 2540 & 13.66 & 2454 & 96.61 & 86 & 3.39 & \\
\hline$\geqq 57,801$ & 1766 & 9.49 & 1699 & 96.21 & 67 & 3.79 & \\
\hline \multicolumn{2}{|l|}{ Urbanization of residence area } & & & & & & 0.135 \\
\hline Level 1 & 6593 & 35.44 & 6334 & 96.07 & 259 & 3.93 & \\
\hline Level $2 \& 3$ & 9149 & 49.19 & 8740 & 95.53 & 409 & 4.47 & \\
\hline Level 4 \& 5 & 2145 & 11.53 & 2062 & 96.13 & 83 & 3.87 & \\
\hline Level 6 \& 7 & 714 & 3.84 & 676 & 94.68 & 38 & 5.32 & \\
\hline Catastrophic illnesses & & & & & & & $<0.001$ \\
\hline No & 17,525 & 94.22 & 16,961 & 96.78 & 564 & 3.22 & \\
\hline Yes & 1076 & 5.78 & 851 & 79.09 & 225 & 20.91 & \\
\hline $\mathrm{CCl}$ & & & & & & & $<0.001$ \\
\hline$\leqq 3$ & 4097 & 22.03 & 4022 & 98.17 & 75 & 1.83 & \\
\hline 4 & 1926 & 10.35 & 1891 & 98.18 & 35 & 1.82 & \\
\hline$\geqq 5$ & 12,578 & 67.62 & 11,899 & 94.60 & 679 & 5.40 & \\
\hline Average CCI (Mean, Std) & 6.54 & 3.59 & 6.42 & 3.52 & 9.28 & 4.16 & \\
\hline DCSI & & & & & & & $<0.001$ \\
\hline$\leqq 1$ & 13,650 & 73.38 & 13,269 & 97.21 & 381 & 2.79 & \\
\hline 2 & 2713 & 14.59 & 2564 & 94.51 & 149 & 5.49 & \\
\hline$\geqq 3$ & 2238 & 12.03 & 1979 & 88.43 & 259 & 11.57 & \\
\hline Average DCSI (Mean, Std) & 1.02 & 1.31 & 0.98 & 1.26 & 1.92 & 1.91 & \\
\hline
\end{tabular}

Abbreviations: CCI Charlson Comorbidity Index, DCSI Diabetes Complications Severity Index, PS propensity score It's 30 New Taiwan Dollar (NT\$) per US dollar

Urbanization level of residence area (overall 7 levels; Level 1 was the most urbanized)

The $p$ values less than 0.05 was considered statistically significant 
Table 3 Stratified analyses: relative mortality risks in nursing patients with diabetes and general patients with diabetes

\begin{tabular}{|c|c|c|c|c|c|c|c|c|c|c|}
\hline \multirow[t]{2}{*}{ Variables } & \multicolumn{3}{|c|}{ General patients } & \multicolumn{3}{|l|}{ Nurse } & \multirow{2}{*}{$\begin{array}{l}\text { Adj. HR } \\
\text { (Nurse: GP) }\end{array}$} & \multicolumn{2}{|c|}{$95 \% \mathrm{Cl}$} & \multirow[t]{2}{*}{$P$-value } \\
\hline & Total $(N)$ & Death $(N)$ & Death (\%) & Total $(N)$ & Death $(N)$ & Death (\%) & & & & \\
\hline Total & 16,910 & 752 & 4.45 & 1691 & 37 & 2.19 & 0.53 & 0.38 & 0.74 & $<0.001$ \\
\hline \multicolumn{11}{|l|}{ Age } \\
\hline$<35$ & 4016 & 99 & 2.47 & 392 & 2 & 0.51 & 0.23 & 0.06 & 0.91 & 0.037 \\
\hline $35-44$ & 5069 & 176 & 3.47 & 499 & 6 & 1.20 & 0.35 & 0.16 & 0.80 & 0.012 \\
\hline $45-54$ & 5494 & 185 & 3.37 & 565 & 10 & 1.77 & 0.57 & 0.30 & 1.08 & 0.085 \\
\hline $55-64$ & 1717 & 125 & 7.28 & 177 & 6 & 3.39 & 0.51 & 0.22 & 1.15 & 0.106 \\
\hline$\geqq 65$ & 614 & 167 & 27.20 & 58 & 13 & 22.41 & 0.91 & 0.51 & 1.60 & 0.735 \\
\hline \multicolumn{11}{|l|}{$\mathrm{CCl}$} \\
\hline$<6$ & 7370 & 154 & 2.09 & 700 & 4 & 0.57 & 0.29 & 0.11 & 0.78 & 0.014 \\
\hline$\geqq 6$ & 9540 & 598 & 6.27 & 991 & 33 & 3.33 & 0.59 & 0.41 & 0.83 & 0.003 \\
\hline \multicolumn{11}{|l|}{ DCSI } \\
\hline$\leqq 1$ & 12,358 & 364 & 2.95 & 1292 & 17 & 1.32 & 0.40 & 0.25 & 0.65 & $<0.001$ \\
\hline 2 & 2491 & 141 & 5.66 & 222 & 8 & 3.60 & 0.70 & 0.34 & 1.44 & 0.334 \\
\hline$\geqq 3$ & 2061 & 247 & 11.98 & 177 & 12 & 6.78 & 0.72 & 0.40 & 1.29 & 0.267 \\
\hline
\end{tabular}

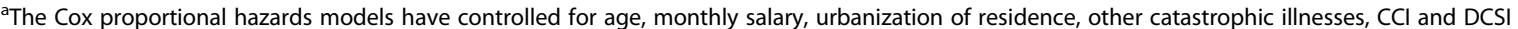

\section{Discussion}

In this study, utilizing the Cox proportional hazards model indicated (Table 3) that the nursing professionals with diabetes had lower mortality risks compared with the general patients with diabetes (Adj. HR: 0.53). Using the propensity score matching, the nursing professionals' cohort and the general patients' control group were similar in terms of demographics, health status, and their socio-economic status $(\mathrm{P}>0.05)$. The two groups may have differed in terms of their knowledge, their attitude, and their practice of health care. We found that nurses had lower mortality risks possibly because nursing professionals have more medical knowledge, which was consistent with the results of previous studies with physicians [8]. Nursing professionals diagnosed with diabetes play a dual role as both providers and recipients of health care. Due to the health care knowledge that they possess, nursing professionals are more likely to adopt active and positive health care attitudes when diagnosed with chronic diseases. In addition, they are more capable

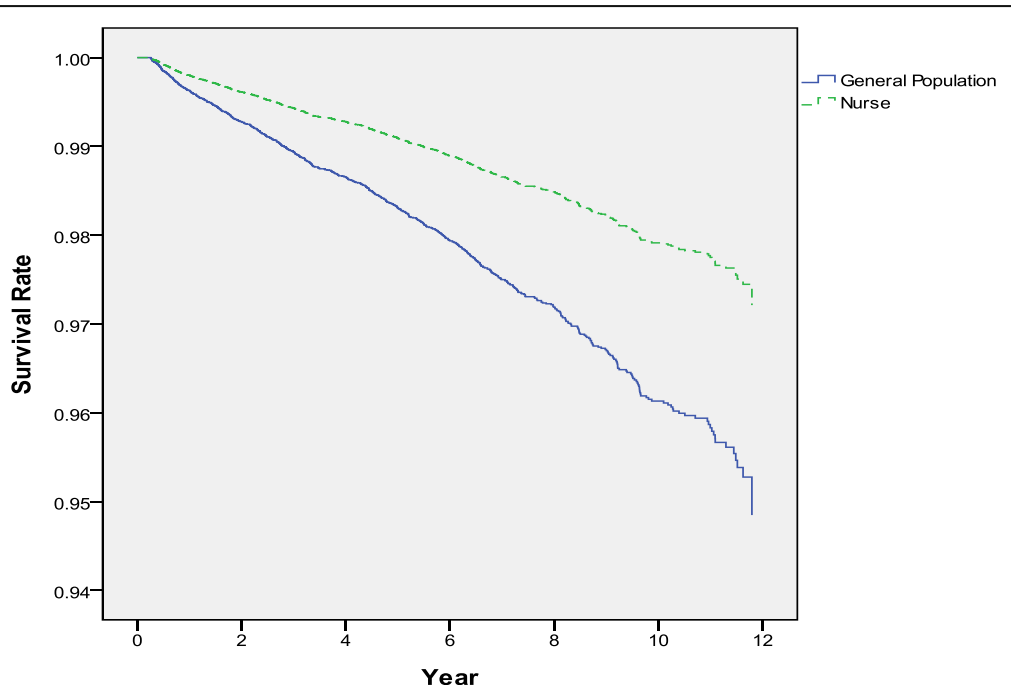

Fig. 1 Relative mortality risk of nursing professionals with diabetes and general patients with diabetes (Cox proportional hazards model was used to control for age, monthly salary, urbanization of residence, other catastrophic illnesses, CCI and DCSI) 
Table 4 Factors that affect the mortality of nursing professionals with diabetes

\begin{tabular}{|c|c|c|c|c|c|c|}
\hline \multirow{2}{*}{$\frac{\text { Variables }}{\text { Age }}$} & \multirow[t]{2}{*}{ Unadj. HR } & \multirow[t]{2}{*}{$P$-value } & \multirow[t]{2}{*}{ Adj. HR } & \multicolumn{2}{|c|}{$95 \% \mathrm{Cl}$} & \multirow[t]{2}{*}{$P$-value } \\
\hline & & & & & & \\
\hline$<35$ (reference) & & & & & & \\
\hline $35-44$ & 2.28 & 0.313 & 1.79 & 0.35 & 9.18 & 0.487 \\
\hline $45-54$ & 3.60 & 0.098 & 2.76 & 0.58 & 13.13 & 0.202 \\
\hline $55-64$ & 6.93 & 0.018 & 3.31 & 0.63 & 17.36 & 0.157 \\
\hline$\geqq 65$ & 48.29 & $<0.001$ & 23.54 & 5.02 & 110.33 & $<0.001$ \\
\hline \multicolumn{7}{|l|}{ Monthly salary (NT\$) } \\
\hline \multicolumn{7}{|c|}{$\leqq 17,280$ (reference) } \\
\hline $17,281 \sim 22,800$ & 0.50 & 0.219 & 0.98 & 0.30 & 3.17 & 0.967 \\
\hline $22,801 \sim 28,800$ & 1.10 & 0.856 & 1.37 & 0.45 & 4.21 & 0.579 \\
\hline $28,801 \sim 36,300$ & 0.52 & 0.308 & 1.01 & 0.26 & 3.98 & 0.989 \\
\hline $36,301 \sim 45,800$ & 0.31 & 0.050 & 0.75 & 0.21 & 2.73 & 0.667 \\
\hline $45,801 \sim 57,800$ & 0.43 & 0.194 & 0.58 & 0.15 & 2.19 & 0.422 \\
\hline$\geqq 57,801$ & 0.35 & 0.202 & 0.45 & 0.09 & 2.39 & 0.351 \\
\hline \multicolumn{7}{|l|}{ Urbanization of residence area } \\
\hline \multicolumn{7}{|c|}{ Level 1 (reference) } \\
\hline Other Level & 0.79 & 0.476 & 1.14 & 0.56 & 2.33 & 0.724 \\
\hline \multicolumn{7}{|l|}{ Catastrophic illnesses } \\
\hline \multicolumn{7}{|l|}{ No (reference) } \\
\hline Yes & 5.82 & $<0.001$ & 6.90 & 2.92 & 16.29 & $<0.001$ \\
\hline \multicolumn{7}{|l|}{$\mathrm{CCl}$} \\
\hline \multicolumn{7}{|l|}{$<5$ (reference) } \\
\hline$\geqq 5$ & 4.61 & 0.011 & 1.29 & 0.37 & 4.55 & 0.688 \\
\hline \multicolumn{7}{|l|}{ DCSI } \\
\hline \multicolumn{7}{|l|}{$\leqq 1$ (reference) } \\
\hline 2 & 2.70 & 0.021 & 2.20 & 0.91 & 5.27 & 0.078 \\
\hline$\geqq 3$ & 4.79 & $<0.001$ & 2.72 & 1.20 & 6.16 & 0.017 \\
\hline
\end{tabular}

Abbreviations: CCI Charlson Comorbidity Index, DCSI Diabetes Complications Severity Index, PS propensity score It's 30 New Taiwan Dollar (NT\$) per US dollar

Urbanization level of residence area (overall 7 levels; Level 1 was the most urbanized)

The $p$ values less than 0.05 was considered statistically significant

of adjusting their lifestyles, and therefore, they have lower mortality risks compared with general patients that are diagnosed with diabetes. This finding confirmed the knowledge, attitude, and practice theory [20-22].

On an average, nursing professionals suffered from newly onset diabetes at a younger age than general patients $(42.01 \pm 12.03$ y vs. $59.29 \pm 13.11$ y), possibly because nursing professionals have to work in shifts. Niedhammer et al. [23] found that nursing professionals who worked in night shifts were more likely to gain weight and become overweight. Other studies $[24,25]$ have also discovered that working shifts could result in an increased risk of metabolic diseases. Timothy et al. [26] claimed that shift work was a risk factor for diabetes.
However, when the nurses and the general patients were diagnosed with diabetes, we found that the nursing professionals were healthier than the other women in terms of their DCSI score $(0.37 \pm 0.78$ vs. $0.54 \pm 0.98$, Table 1), which suggests a screening bias; either the nurses received the diagnosis prematurely and/or the others received it later, because the awareness of the disease could be more pronounced among the nurses due to their medical knowledge. In addition, the nurses could be more aware of the importance of preventive strategies once the disease has been diagnosed, giving them a better prognosis as compared to the others, e.g., lower mortality risks in the younger age strata.

After we used propensity score matching, the nursing professionals with diabetes had no significant difference 
that was observed between mortality risks in diabetic nursing professionals and general patients above 45 years of age (Table 3), possibly because of a familial tendency or that combined with environmental influences [27]. This is also possibly because the capability to adjust lifestyles decreases with age. In addition, knowledge cannot always affect attitude nor can positive patient care (practice) always be performed [28, 29].

An analysis regarding factors that influence mortality in nursing professionals diagnosed with diabetes (Table 4) showed that nursing professionals that were older, had catastrophic illnesses, or had high DCSI exhibited higher mortality risks. The results were consistent with those of previous studies [30,31]. The analysis of monthly salaries indicated that this variable had no significant influence on the mortality risks in nursing professionals with diabetes. This result disagreed with that of Kposowa [32], who investigated the relationship between financial status and mortality by examining 527,426 U.S. patients with diabetes. Kposowa discovered that financial status and income were crucial factors that affected mortality in patients with diabetes. Specifically, people with a lower financial status exhibited higher mortality rates. In this study, monthly salary had no significant influence on the mortality risks in nursing professional with diabetes possibly because all nursing professionals had similar levels of medical education and patient care knowledge; therefore, the approaches and quality of care they received were similar. Consequently, although nursing professionals with higher monthly salaries had relatively low mortality risks, this difference did not reach the level of significance.

\section{Limitations}

The study has the following several limitations: (1) only data from the NHIRD were examined, and factors such as the lifestyles and health behavior of the patients were not considered. Therefore, we used the propensity score matching to avoid a selection bias from confounding variables in observational studies and imitate the results of a randomized controlled trial [33]. The longitudinal database provides a better opportunity for accumulation of data concerning nursing professionals with diabetes and survival analyses; and (2) no clinical data were obtained to verify the accuracy of the diabetes classification in the NHIRD, where the International Classification of Diseases-9 codes were applied. To overcome the second limitation, we adopted rigorous classification criteria: patients with diabetes were defined as people that had been diagnosed with diabetes during primary or secondary diagnosis (ICD-9-CM: 250 or A-code: A181) and had made 3 or more clinic visits or been hospitalized at least once within 365 days [15].
In this study, because each nurse's number of years of service and shift lengths was unknown, the correlation between their shift work and diabetes mortality risk could not be determined, which is another limitation.

\section{Conclusion}

This study is the first attempt to use NHIRD data for analyzing relative mortality risks in nursing professionals with diabetes and general patients with diabetes. Patients with Type 2 diabetes treatment would not leave their medical care service insurance, especially under a universal health insurance program. The results showed that although nursing professionals were diagnosed with diabetes at younger ages, they had lower mortality risks compared with general patients with diabetes in their age groups. Health professionals may have more medical knowledge regarding earlier screening and disease control and prevention than others. The nursing professionals may use their own professional knowledge to engage in healthy lifestyles in a way that reduces their risk of illness.

Nursing professionals working at clinics must deal with heavy workloads and shift work and are therefore prone to occupational hazards. Stress and shift work are risk factors for diabetes. The results of this study can serve as a reference for understanding the occupational hazards encountered by nursing professionals and for devising plans for improving the health of nursing professionals. In addition, the results also can serve as a reference for developing heath education.

\section{Abbreviations}

CCI: Charlson Comorbidity Index; CI: Confidence interval; DCSI: Diabetes complication severity index; HR: Hazard ratio; ICD: International Statistical

Classification of Diseases; IDF: International Diabetes Federation; NHI: National Health Insurance; NHIRD: NHI Research Database; NT\$: New Taiwan Dollar; PS: Propensity score; US: United States

\section{Acknowledgments}

We are grateful for use of the National Health Insurance Research Database provided by the National Health Research Institutes. The interpretations and conclusions contained herein do not represent those of the Ministry of Health and Welfare, Taiwan, R.O.C.

\section{Funding}

This study was supported by the grant (CMU102-ASIA-12) from China Medical University and Asia University as well as the grant (DOH 10216) from Ministry of Health and Welfare.

\section{Availability of data and materials}

Data are available from the National Health Research Institutes (NHRI), Taiwan. All interested researchers can obtain the databases published and managed by the NHRI. All researchers are allowed to use the databases for their studies if they are interested in using the data. Before using the databases for research, all studies should get the IRB permission.

\section{Authors' contributions}

$\mathrm{HLH}$ and WCT wrote the draft and finalized the manuscript, researched data and contributed to discussions. PTK and WYC analyzed the data. CYK, CCP and SMW organized the study, and reviewed and edited the manuscript. All authors read and approved the final manuscript. 


\section{Competing interests}

The authors declare that they have no competing interests.

\section{Consent for publication}

Not applicable.

\section{Ethics approval and consent to participate}

The institutional review board of China Medical University approved this study (IRB No.: CMUH 20130326C).

\section{Author details}

'Department of Aged Welfare and Social Work, Toko University, Taiwan, Republic Of China. ${ }^{2}$ Department of Public Health and Department of Health Services Administration, China Medical University, Taiwan, Republic Of China. ${ }^{3}$ Department of Nursing, Hengchun Tourism Hospital, Ministry of Health and Welfare, Taiwan, Republic Of China. ${ }^{4}$ Department of Urology, Hengchun Tourism Hospital, Ministry of Health and Welfare, Taiwan, Republic Of China. ${ }^{5}$ Department of Healthcare Administration, Asia University, Taichung, Taiwan, Republic Of China. ${ }^{6}$ Department of Health Services Administration, China Medical University, 91, Hsueh-Shih Road, Taichung, Taiwan 40402, Republic Of China.

Received: 9 May 2016 Accepted: 30 September 2016

Published online: 06 October 2016

\section{References}

1. International Diabetes Federation. About diabetes. Risk factors. 2014. http://www.idf.org. Accessed 10 Nov 2015.

2. Ministry of Health and Welfare. 2012 statistics of causes of death. 2014. http://www.mohw.gov.tw/EN/Ministry/Statistic. Accessed 2 May 2016.

3. Guariguata L, Whiting D, Hambleton I, Beagley J, Linnenkamp U, Shaw J. Global estimates of diabetes prevalence for 2013 and projections for 2035 for the IDF Diabetes Atlas. Diabetes Res Clin Pract. 2013;103(2):137-49.

4. Lindström J, Peltonen M, Eriksson J, llanne-Parikka P, Aunola S, KeinänenKiukaanniemi S, et al. Improved lifestyle and decreased diabetes risk over 13 years: long-term follow-up of the randomised Finnish Diabetes Prevention Study (DPS). Diabetologia. 2013;56(2):284-93.

5. Frank E, Biola H, Burnett CA. Mortality rates and causes among US physicians. Am J Prev Med. 2000;19(3):155-9.

6. Carpenter LM, Swerdlow AJ, Fear NT. Mortality of doctors in different specialties: findings from a cohort of 20000 NHS hospital consultants. Occup Environ Med. 1997;54(6):388-95.

7. Radon K, Goldberg M, Becklake M. Healthy worker effect in cohort studies on chronic bronchitis. Scand J Work Environ Health. 2002;28(5):328-32.

8. Chiou S-J, Kung P-T, Naessens JM, Huang K-H, Chang Y-C, Wang Y-H, Tsai W-C. Do physicians with diabetes have differences in dialysis use and survival than other patients with diabetes. Diabetes Res Clin Pract. 2014:105(3):382-90

9. Blaber AY. Exercise: who needs it? Br J Nurs. 2005;14(18):973-5.

10. National Health insurance Administration, Ministry of Health and Welfare. Statistics \& Surveys. 2013. http://www.nhi.gov.tw. Accessed 20 Aug 2015.

11. Cheng T-M. Taiwan's new national health insurance program: genesis and experience so far. Health Aff. 2003;22(3):61-76.

12. Lu J-FR, Hsiao WC. Does universal health insurance make health care unaffordable? Lessons from Taiwan. Health Aff. 2003;22(3):77-88.

13. Tung Y-C, Chang G-M, Chen Y-H. Associations of physician volume and weekend admissions with ischemic stroke outcome in Taiwan: a nationwide population-based study. Med Care. 2009;47(9):1018-25.

14. Hsu Y, Tang W, Chang Y, Maa S. A preliminary study of the work values of male nurses in Taiwan and related factors. Hu li za zhi j nursi. 2013;60(2):50-60.

15. Chang C, Shau W, Jiang Y, Li H, Chang T, H-H Sheu W, Kwok C, Ho L, Chuang L. Type 2 diabetes prevalence and incidence among adults in Taiwan during 1999-2004: a national health insurance data set study. Diabet Med. 2010;27(6):636-43.

16. Liu C, Hung Y, Chuang Y, Chen Y, Weng W, Liu J, Liang K. Incorporating development stratification of Taiwan townships into sampling design of large scale health interview survey. J Health Manag. 2006;4(1):1-22.

17. National Health insurance Administration, Ministry of Health and Welfare. Statistics \& Surveys. 2013. http://www.nhi.gov.tw/English/webdata/webdata. aspx?menu=11\&menu_id=296\&webdata_id=1942\&WD_ID=296. Accessed 20 Aug 2015.
18. Deyo RA, Cherkin DC, Ciol MA. Adapting a clinical comorbidity index for use with ICD-9-CM administrative databases. J Clin Epidemiol. 1992;45(6):613-9.

19. Young BA, Lin E, Von Korff M, Simon G, Ciechanowski P, Ludman EJ, Everson-Stewart S, Kinder L, Oliver M, Boyko EJ. Diabetes complications severity index and risk of mortality, hospitalization, and healthcare utilization. Am J Manag Care. 2008;14(1):15.

20. Palaian S, Acharya LD, Rao PGM, Shankar P, Nair NM, Nair NP. Knowledge, attitude, and practice outcomes: evaluating the impact of counseling in hospitalized diabetic patients in India. P AND T. 2006;31(7):383.

21. Joshi A, Mehta S, Grover A, Talati K, Malhotra B, Puricelli Perin DM. Knowledge, Attitude, and Practices of Individuals to Prevent and Manage Metabolic Syndrome in an Indian Setting. Diabetes Technol Ther. 2013;15(8):644-53.

22. Demaio AR, Otgontuya D, de Courten M, Bygbjerg IC, Enkhtuya P, Oyunbileg J, Meyrowitsch DW. Exploring knowledge, attitudes and practices related to diabetes in Mongolia: a national population-based survey. BMC Public Health. 2013;13(1):236.

23. Niedhammer I, Lert F, Marne M. Prevalence of overweight and weight gain in relation to night work in a nurses' cohort. Int J Obes Relat Metab Disord Jlnt Assoc Study Obes. 1996;20(7):625.

24. Karlsson B, Knutsson A, Lindahl B. Is there an association between shift work and having a metabolic syndrome? Results from a population based study of 27485 people. Occup Environ Med. 2001;58(11):747-52.

25. Ika K, Suzuki E, Mitsuhashi T, Takao S, Doi H. Shift Work and Diabetes Mellitus among Male Workers in Japan: Does the Intensity of Shift Work Matter? Acta Med Okayama. 2013;67:25-33.

26. Monk TH, Buysse DJ. Exposure to Shift Work as a Risk Factor for Diabetes. J Biol Rhythms. 2013;28(5):356-9.

27. Chen L, Magliano DJ, Zimmet PZ. The worldwide epidemiology of type 2 diabetes mellitus-present and future perspectives. Nat Rev Endocrinol. 2012:8(4):228-36.

28. Fischer C, Crockett S, Heller K, Skauge L. Nutrition knowledge, attitudes, and practices of older and younger elderly in rural areas. J Am Diet Assoc. 1991;91(11):1398-401.

29. Livingston P, McCarty C, Taylor H. Knowledge, attitudes, and self care practices associated with age related eye disease in Australia. $\mathrm{Br} \mathrm{J}$ Ophthalmol. 1998;82(7):780-5.

30. Walker J, Brewster D, Colhoun H, Fischbacher C, Lindsay R, Wild S. Causespecific mortality in Scottish patients with colorectal cancer with and without type 2 diabetes (2000-2007). Diabetologia. 2013;56(7):1531-41.

31. Chen TT, Chung KP, Lin I, Lai MS: The Unintended Consequence of Diabetes Mellitus Pay-for-Performance (P4P) Program in Taiwan: Are Patients with More Comorbidities or More Severe Conditions Likely to Be Excluded from the P4P Program? Health Serv Res 2011, 46 (1p1):47-60.

32. Kposowa AJ. Mortality from Diabetes by Hispanic Groups: Evidence from the US National Longitudinal Mortality Study. Int J Popul Res. 2013;2013:12.

33. Austin PC. An introduction to propensity score methods for reducing the effects of confounding in observational studies. Multivar Behav Res. 2011;46(3):399-424.

\section{Submit your next manuscript to BioMed Central and we will help you at every step:}

- We accept pre-submission inquiries

- Our selector tool helps you to find the most relevant journal

- We provide round the clock customer support

- Convenient online submission

- Thorough peer review

- Inclusion in PubMed and all major indexing services

- Maximum visibility for your research

Submit your manuscript at www.biomedcentral.com/submit
Biomed Central 